\title{
Integration of conventional cell viability assays for reliable and reproducible read-outs: experimental evidence
}

\author{
Sukant Garg ${ }^{1,2}$, He Huifu ${ }^{1,3}$, Sunil C. Kaul ${ }^{1}$ and Renu Wadhwa ${ }^{1,2^{*}}$
}

\begin{abstract}
Objective: Short-term viability assays of cultured cells in 96-well plates are routinely used to determine the cytotoxicity or safety of drugs. These are often based on the formation of chromogen, generated selectively in viable cells. The innate problems of such short-term cell viability assays include (i) effect of drugs is determined by cell density (ii) some drugs have slow/gradual effect and hence may escape such assays, (iii) cell morphology that reveal significant hints to molecular signaling underlining the effect of drugs cannot be effectively captured, (iv) long-term effect on viability and clonogenic potential of cells cannot be determined and (v) herbal extracts often possess intrinsic color that interferes with spectrophotometer estimation. In light of the ease and importance of cell culture-based assessment of drug safety and cytotoxicity, we attempted to combine the conventional cell-based assays in a way that allows multiple readouts (quantitative and qualitative) from a single experiment, and avoids the drawbacks of color interference.

Results: We have established and validated (using 16 types of cultured mammalian cells) a Quantitative and Qualitative Cell Viability assay in 12-well cell culture plates. It overcomes several shortcomings as discussed above and allows long-term observations on cell morphology and clonogenicity.
\end{abstract}

Keywords: QCV, Crystal violet, Clonogenicity, Quantitative-qualitative assay

\section{Introduction}

Cancer cells are characterized and distinguished from the normal cells by their potential to proliferate and grow in colonies [1], most usually treated with chemotherapy ranging from months to years [2]. However, most of the chemotherapeutic drugs are toxic to normal cells, and often result into resistance or recurrence [3]. Drug development involves complicated route that initiates with simple viability/cytotoxicity assays performed on cultured cancer and normal cells. Conventionally, these assays are performed in short-term (few hours) and rely on mitochondrial activity of viable cells, linked to reliable

\footnotetext{
*Correspondence: renu-wadhwa@aist.go.jp

${ }^{1}$ DAILAB, DBT-AIST International Center for Translational

and Environmental Research (DAICENTER), National Institute of Advanced Industrial Science \& Technology (AIST), 1-1-1 Higashi, Tsukuba 305-8565, Japan

Full list of author information is available at the end of the article
}

quantitative read-outs [4]. These have been proved very informative for extremely toxic drugs that cause sudden death of cells by apoptosis or autophagy. However, the drugs with slow, but useful, actions such as induction of growth arrest, senescence or differentiation require long term assessment [5-8].

In in vivo conditions, tumor cells grow from a single cell to a densely packed mass that determines the effect of drugs in several ways, therefore should be treated at sparse and dense clonogenic growth conditions. Furthermore, these cytotoxic compounds may cause morphologically accountable stress resulting into responses including sensitization or resistance [9], making cell morphology an important factor to consider cell response. Various metabolic-activity-based methods involving tetrazolium reduction and resazurin reduction have been described as reliable indicators of cell viability [10]. However, each lack universal application. Distinct factors limiting their use include concerns about cost, 
reagent-induced toxicity and operational interference $[10,11]$.

Large investments have been allocated towards identification and development of potential anticancer drug candidates [12]. National Institute of Health financial chart reported expenditure of about 5589 million US dollars in fiscal year 2016, out of which about $10 \%$ was spent on research [13-15]. These stakes are not justified if they do not sum up into successful clinical trials. American Cancer Society has already labeled cancer as an emerging epidemic [16]. This warrants investments in cancer drug discovery programs. Yet, the shrinking budget for medicinal research reflects lack of sophisticated instruments and personnel in small laboratories. We aimed and demonstrate here a technique designed to (i) allow evaluation of the effect of a drug on single cells developing into dense colonies, (ii) eliminate the interference of intrinsic color of the drug in viability measurements, and (iii) allow multiple readouts such as effect on morphology, clonogenicity and/or cytotoxicity in single experiment.

\section{Main text \\ Materials and methods \\ Cell lines}

All the cell lines purchased from JCRB, Japan [17] were carefully selected in order to include a variety from several tissues and diseases. Cells were cultured in a humidified $37{ }^{\circ} \mathrm{C}$ incubator with $5 \% \mathrm{CO}_{2}$ following the supplier's recommendation, as indicated in the Additional files 1 and 2.

\section{Generation of standard curve}

As presented in Additional files 2, 3 and 4, 0-80,000/ well plated $\mathrm{C} 6$ cells were trypsinized, counted manually using cell counter $\left(\mathrm{TC} 20^{\mathrm{TM}}\right.$ Automated Cell Counter, BioRad) in the 1st plate, and fixed with ice cold methanol: acetone (1:1) [18] in the 2nd plate, followed by staining, washing, air-drying, de-staining, and measurement of optical density in a 96-well plate at $570 \mathrm{~nm}$ using a spectrophotometer (Tecan Infinite $200^{\circledR}$ Pro, Tecan Group Ltd., Mannedorf, Switzerland). Finally, a scatter graph was plotted using optical density against cell number to obtain $c$ (y-intercept) and $m$ (slope) values (Additional file 1).

MTT-based short- and long-term cell viability and microscopy C6 or U2OS cells $\left(1 \times 10^{3} /\right.$ well $)$ were plated in a 96-well plate and allowed to settle overnight, followed by treatment with DMEM supplemented with or without colored cytotoxic extract labelled CN-04 (Cinnamomum verum stem extract) or HA-05 (Helicteres angustifolia root extract). The control or extract-treated cells were incubated at $37{ }^{\circ} \mathrm{C}$ and $5 \% \mathrm{CO}_{2}$. After $48 \mathrm{~h}$, cell pictures were recorded at $40 \times$ magnification followed by washing with $200 \mu \mathrm{L}$ PBS (twice) and replacement with fresh culture medium. $10 \mu \mathrm{L}$ of MTT (M2128, Sigma-Aldrich) in phosphate buffered saline (PBS; $2 \mathrm{mg} / \mathrm{mL}$ ) was added to each well and incubated at same conditions for $4 \mathrm{~h}$. All the media was aspirated and replaced with $100 \%$ DMSO, and optical density was measured at $570 \mathrm{~nm}$. Cell viability and standard deviation were calculated using Microsoft Office $2016^{\circledR}$. Growth efficiency of live cells over long term (15-20 population doublings) in a 96-well plate was determined by the same method. 200-1000 C6 cells/ well were plated in 96-well plates (4 sets) and allowed to settle overnight, followed by change in growth medium every alternate day. After every $48 \mathrm{~h}$, cell viability was calculated in one set each. At the end, cell viability trend, standard deviation, slope equation and $R^{2}$ values were collectively calculated.

\section{Qualitative and Quantitative Cell Viability (QCV) assay}

As presented in Additional files 3 and 4, C6 cells (100/ well) were plated in a 12-well plate and incubated until the appearance of colonies (8-10 days) with regular change in the culture medium with/without the colored extract $\mathrm{CN}-04(0.25-0.75 \%)$ or colorless compound CB-01 (Cucurbitacin B, $1 \mu \mathrm{M}$ suspension in 100\% DMSO, $0.5 \%$ ) every alternate day. Cells and colonies were fixed using ice cold methanol: acetone (1:1) [18], followed by staining with crystal violet, washing, air-drying, phase contrast microscopy at $40-400 \times$ magnification, colony counting, de-staining, and measurement of optical density in a 96-well plate at $570 \mathrm{~nm}$ using the spectrophotometer. Colonies were averaged. Using the equation \{ cell number $=(O D-c) / m\}$, average of long term cytotoxicity was obtained, where $\mathrm{c}$ and $\mathrm{m}$ are the $\mathrm{y}$-intercept and slope values for $\mathrm{C} 6$ cells obtained in the generation of the standard curve section (Additional file 1).

\section{Statistics}

All the experiments were performed in triplicates. Statistical analysis was performed using GraphPad $^{\circledR}(2017)$ software, Inc. (California, USA), and depicted as * $<0.05$, $* 0.01$, and $* *<0.001$. Unpaired $t$ test was done using mean, standard deviation and the number of independent experiments.

\section{Results}

Growth characteristics of cells were determined for sixteen cell lines (Additional file 1). The optical densities were plotted to obtain standard curves and slope (y-intercept values). In our regular cell viability assays using MTT, we observed that the drug response is driven by cell density to a large extent. Hence, we examined the effect of cell density on growth or drug 
response in a time dependent manner. Due to fast growing properties (population doubling time $\sim 10-12 \mathrm{~h}$ ) that gives quick results, adequate for experimental validation, we selected rat glioma cells for the study. Cells plates at spare density formed macroscopically visible colonies in 7-8 days. Therefore, to enable the treatment of C6 cells individually as well as in colonies, a minimum of 8 days experiment was designed. This criterion also allowed us to monitor the effect of slowacting compounds and add pragmatism to the actual in vitro/in vivo conditions to some extent. The experiments initiated with $200 \mathrm{C} 6$ cells showed the most efficient growth in 8 days followed by cell density/adhesion dependent growth inhibition (Fig. 1a). Trend-line slope, $y$-intercept and $R^{2}$ values showed that the 200 cells/ well could qualify to be significant (criteria to qualify $=R^{2}>98 \%$ ) (Fig. 1b). However, seeding of 200 cells per well in 96-well plate is considered low and likely to give high probability of experimental errors [10]. We next used plant extract HA-05 that possessed color. In independent $48 \mathrm{~h}$ MTT-based assays, we found that its color interfered with the optical density (Fig. 1c). Whereas low doses of the extract showed cytotoxicity by means of optical density measurement, the high doses showed increase in viability. Microscopic evaluation showed a clear dose dependent decrease in cell density as well as stressed morphology. Similar results were obtained with another colored compound $\mathrm{CN}-04$ (Fig. 1d). Such errors in the readouts as a result of color caught our attention and urged remodeling of assays.

We recruited conventional MTT-based viability and our QCV assays on C6 cells treated with CN-04. MTT assay showed a discrepancy in the readings. Whereas cells treated with $0.25 \% \mathrm{CN}-04$ showed an increase in cell viability (Fig. 2a), microscopic observations showed cell death. In order to confirm the possibility of interference of the color, the extract (without cells) was incubated overnight in the same conditions and quantitated as in MTT assay. We found that the optical density from the wells corresponded directly with the dose of the extract (Fig. 2b). On the other hand, QCV determined cell viability (absolute cell count), morphological condition and the
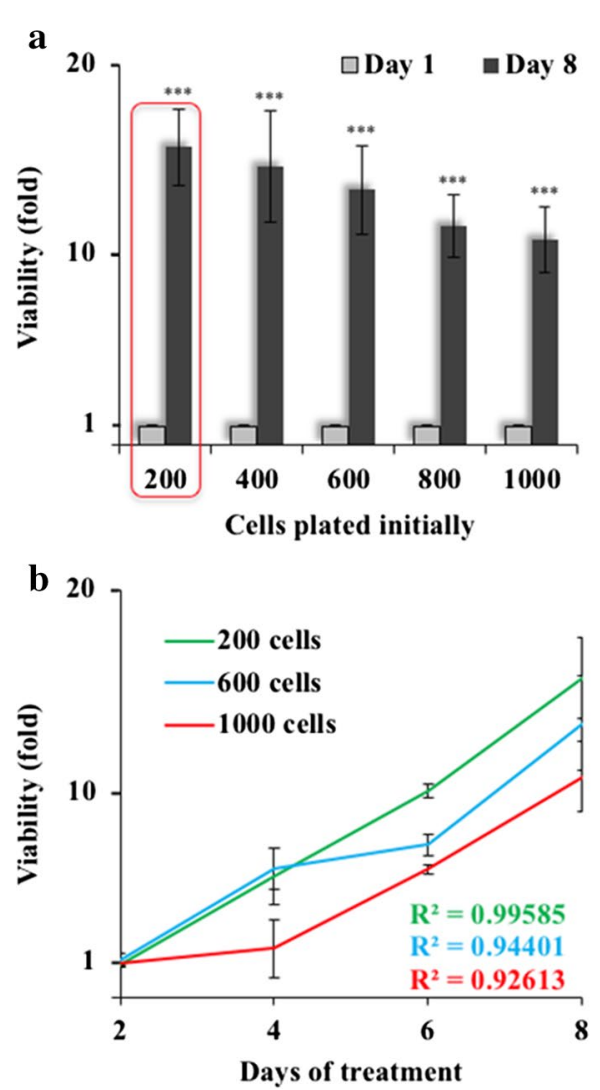

\section{c MTT-based cytotoxicity assay, $48 \mathrm{~h}$ treatment}

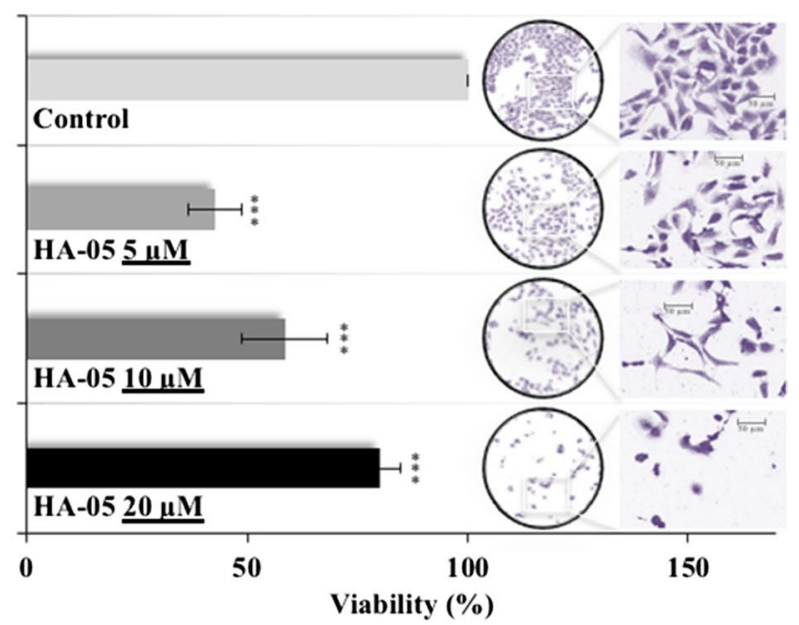

d

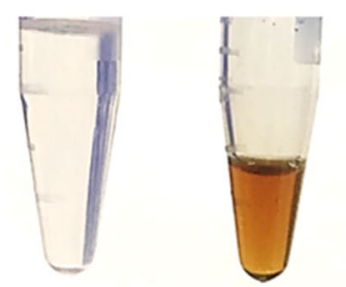

$100 \%$ DMSO HA-05 $100 \%$

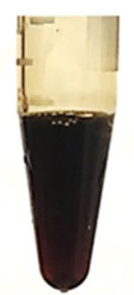

CN-04 100\%

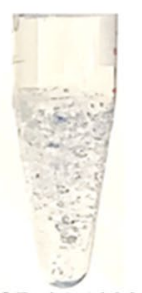

CB-01 $100 \%$

Fig. 1 Interference of cell number and color of the test reagent in the cytotoxicity assays. a Cell viability after 8 days of culture in a 96-well plate well. $\mathbf{b}$ Cell growth pattern over 8 days in a 96-well plate, and $\mathbf{c}$ Cell viability after $48 \mathrm{~h}$ treatment with colored extract HA-05 (left) and cell pictures (right) against control recorded at $\times 40$ magnification. $\mathbf{d}$ Images of the colored extracts and colorless compounds. Statistical analysis is depicted as ${ }^{*}<0.05,{ }^{* *} 0.01$, and ${ }^{* * *}<0.001$ 


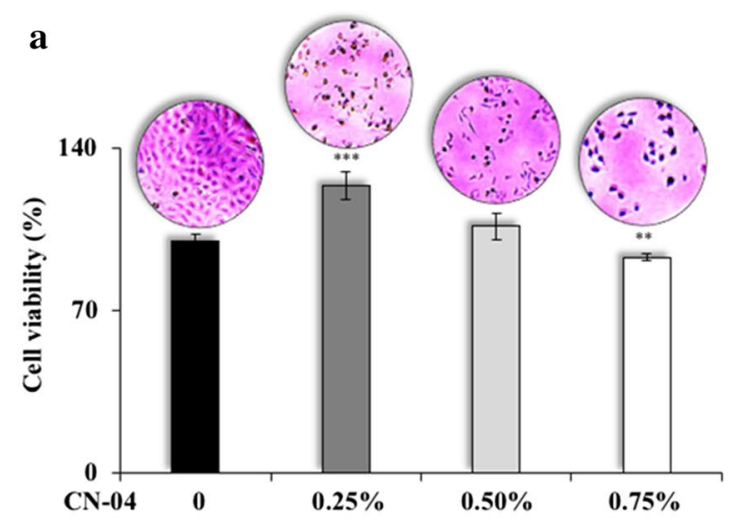

b
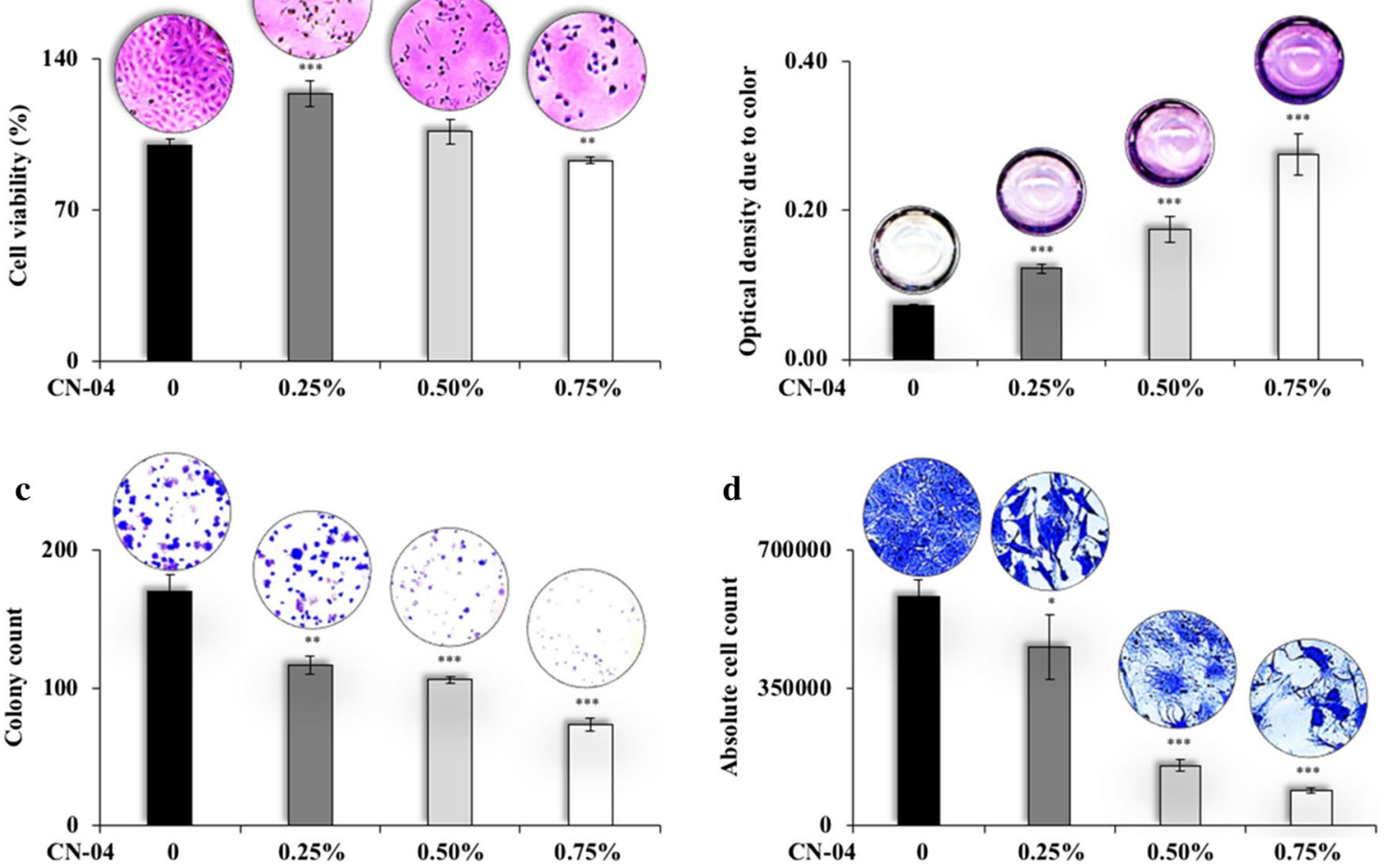

Fig. 2 Determination of cytotoxicity of a colored reagent by conventional MTT assays, institution of QCV assay. a Viability of cells treated with the reagent for $48 \mathrm{~h}$ showed haphazard pattern, while the cell pictures recorded at $\times 40$ magnification showed dose-dependent cytotoxicity. $\mathbf{b}$ Dose-dependent increase in optical density was observed as a result of color of the reagent. $\mathbf{c}, \mathbf{d}$ Colony number and quantitative cell number determined by dissolving crystal violet stain, and the morphology of the cells recorded at $\times 40$ magnification correlated with each other proportionately. Statistical analysis is depicted as ${ }^{*}<0.05,{ }^{* *} 0.01$, and ${ }^{* * *}<0.001$

colony forming potential of the cells treated with $\mathrm{CN}-04$ $0.25-0.75 \%$ over 8 -day period showed consistent results (Fig. 2c, d).

In order to validate QCV assay for colorless agents, we performed colony formation assay using $0.5 \%$ of CB-01 (colorless cytotoxic compound). Besides the decrease in clonogenic potential, we confirmed considerable difference in the morphology of the treated cells against the control group (Fig. 3a-c). Optical density readout after de-staining revealed long-term quantifiable cell viability. Using the slope $(\mathrm{m})$ and $y$-intercept $(\mathrm{c})$ values given in Additional file 1, we calculated the absolute cell count in control and treated cells (Fig. 3d). Moreover, we found that the reduction in clonogenicity and viability in response to the treatment were not the same. While only $\sim 35 \%$ colonies (Fig. 3c) remained after 8-days of treatment and culture, $\sim 65 \%$ cells (Fig. $3 \mathrm{~d}$ ) in total survived, indicating plausible presence of individual, scattered and unperceivable cells within the well. Since these results suggest that the colony number and the absolute cell count are two independent entities, they must be noted separately.
In summary, we found that the QCV assay accounts for (i) cell count in direct proportional to the cell density and with no discrepancies due to the color of extract, (ii) additional readouts such as monitoring cell morphology and clonogenicity assessment making QCV assay more cost-effective, and (iii) convenient to measure the cell number and colony counts as independent records.

\section{Discussion}

Conventional viability assays for cultured cells are the essential step in drug discovery protocols and may account for establishment of chemotherapeutic dose of the drugs in the clinics [19]. Most of these involve the application of intracellular metabolism altering reagents that are further complicated by drug and/or chromogen characteristics and interactions, such as crystallization, chemical interference, membrane permeability alteration, toxicity, and formazan fabrication with variable in vitro conditions with drug treatments [20-22]. Such hurdles have been implicated for many drugs [23], which may act slowly and demand time and dose dependent response over a relatively longer period [24]. To circumvent these 


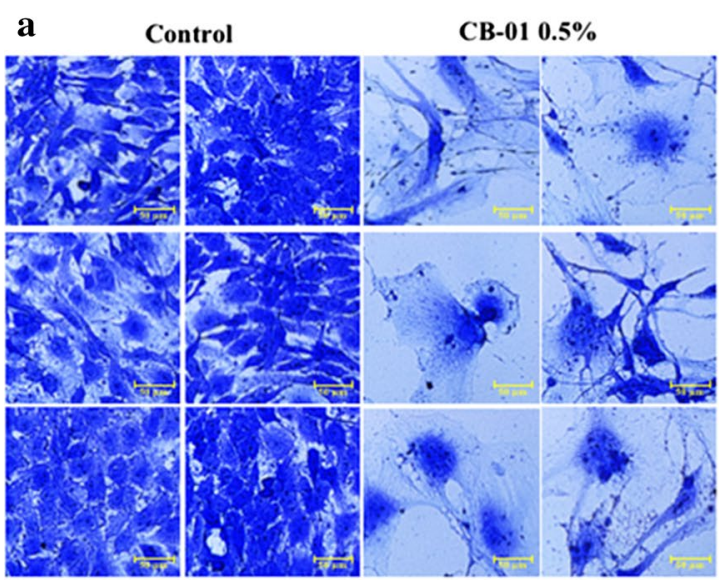

CV stain

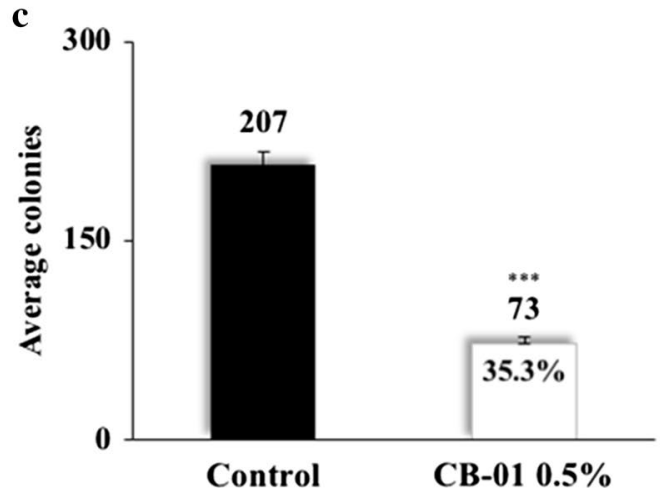

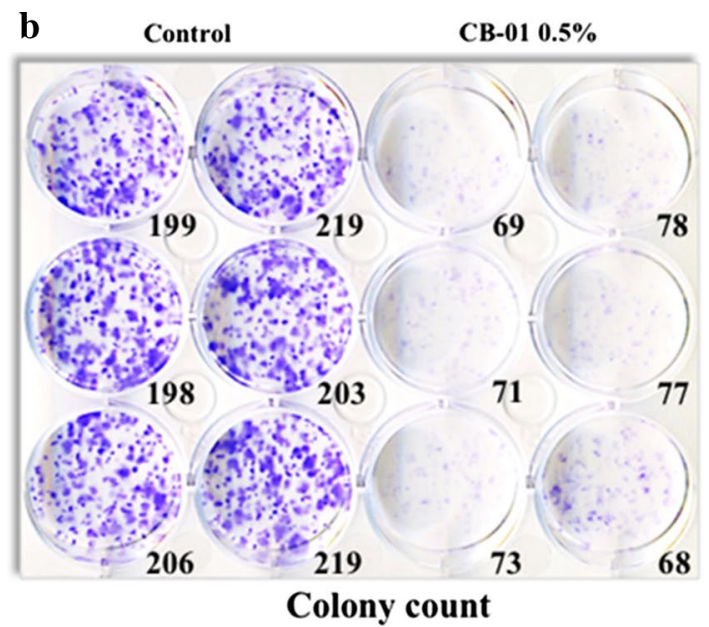

d

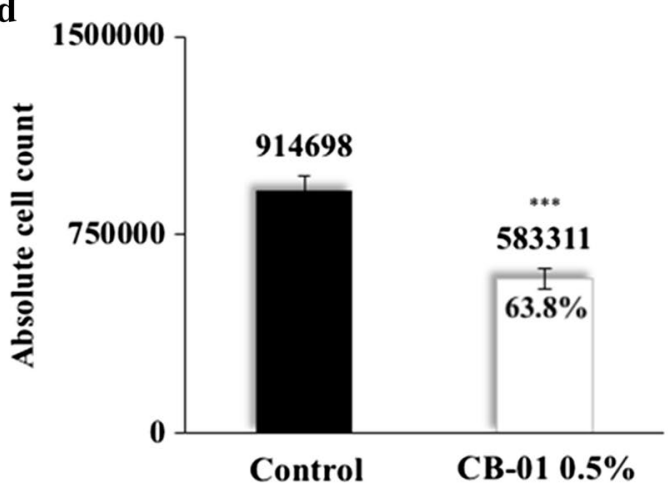

Fig. 3 Validation of QCV assay: a Crystal violet stained cell pictures recorded at $\times 400$ magnification at the end of 8 days treatment are shown. $\mathbf{b}$ Manually counted cell colonies in six variants of control and treated wells. c Quantified colony number, and $\mathbf{d}$ Quantified absolute cell count by dissolving crystal violet in de-staining solution and using slope equation for C6 cells. Statistical analysis is depicted as ${ }^{*}<0.05,{ }^{* *} 0.01$, and ${ }^{* * *}<0.001$

difficulties, we assimilated the standard assays to yield a more precise and informative, quantifiable and reliable readout from a single experiment.

Based on the cell growth characteristics (Additional files 1 and 2), we chose C6 cells as they grew fast and yielded rapid validation. Each $\mathrm{C} 6$ cell (population doubling time $\sim 12 \mathrm{~h}$ ) was expected to multiply to about $65 \times 10^{3}$ cells and make a small colony within 8 days. Therefore, to evaluate the effect of drug on single cells and colonies, the 96-well plates were considered inappropriate and experiment was performed in 12-well plates. We plated 100 cells per well in 12-well plates and subjected to treatment regime of 8 days with change in medium every alternate day. These criteria would allow the evaluation of slow-acting compounds rationalizing their activity in in vivo conditions to some extent. We found that the QCV was more consistent than the conventional MTT assay. We assumed the $\mathrm{R}^{2}$-value of more than $98 \%$ to be considered significant (more than $85 \%$ of standard deviation explained) $[25,26]$.

In QCV assay, it is possible to examine the effect of drugs in short as well as longer span of time in terms of viability and clonogenic potential of cells, irrespective of the cell size. Such readouts are more relevant to the cancer therapy regimens, especially those of natural origin and with slow mechanism of action-weeks to months [27]. QCV assay allows observations on cell morphology to envisage drug response characteristics [28-30]. Evaluation based on fixed cells account for absolute cell count instead of only the metabolically viable; multidimensional aspects depict economic performance $[12-15,31]$. 


\section{Limitations}

The present method may not be suitable for highthroughput screening.

\section{Additional files}

Additional file 1. QCV standardization and determination of slope/yintercept and $R^{2}$ value in 16 cell lines.

Additional file 2. Cell lines, history of disease and conditions of incubation throughout the experiments.

Additional file 3. Schematic presentation of the protocol. A. Determination of standard curve and slope equation. B. QCV assay to determine cell viability, colony forming potential and cell morphology after long-term culture of cells.

Additional file 4. Step-by-step protocol of the QCV assay - determination of standard curve and slope equation, and three experiments turned into a single protocol.

\section{Abbreviations}

QCV: Quantitative and Qualitative Cell Viability; JCRB: Japanese Collection of Research Bioresources Cell Bank; MTT: 3-(4,5-dimethylthiazol-2-yl)-2,5-diphenyltetrazolium bromide; CB: Cucurbitacin B; CV: crystal violet.

\section{Authors' contributions}

SG, SCK, RW conceived and designed the experiments: SG, HH performed the experiments: SG, HH, SCK, RW analyzed the data: SCK, RW contributed reagents/materials: SG, SCK, RW carried out writing, reviewing and editing. All authors read and approved the final manuscript.

\section{Author details}

1 DAILAB, DBT-AIST International Center for Translational and Environmental Research (DAICENTER), National Institute of Advanced Industrial Science \& Technology (AIST), 1-1-1 Higashi, Tsukuba 305-8565, Japan. ${ }^{2}$ School of Integrative \& Global Majors, University of Tsukuba, Tsukuba 305-8577, Japan.

${ }^{3}$ Graduate School of Life \& Environmental Sciences, University of Tsukuba, Tsukuba 305-0006, Japan.

\section{Acknowledgements}

No applicable.

\section{Competing interests}

The authors declare that they have no competing interests.

\section{Availability of data and materials}

All data generated and/or analyzed during this study are included in this published article.

\section{Consent for publications}

Not applicable.

\section{Ethics approval and consent to participate}

Not applicable.

\section{Funding}

This work was supported by the Department of Biotechnology (Government of India) and National Institute of Advanced Industrial Science \& Technology (AIST), Japan.

\section{Publisher's Note}

Springer Nature remains neutral with regard to jurisdictional claims in published maps and institutional affiliations.

Received: 25 April 2018 Accepted: 18 June 2018

Published online: 22 June 2018
References

1. Hanahan D, Weinberg RA. The hallmarks of cancer. Cell. 2000;100:57-70.

2. Gennari A, Stockler M, Puntoni M, Sormani M, D'amico M, De Censi A, Bruzzi P. Duration of chemotherapy for metastatic breast cancer: a systematic review and meta-analysis of randomized clinical trials. J Clin Oncol. 2011;29:2144-9.

3. Midgley RS, Yanagisawa Y, Kerr DJ. Evolution of nonsurgical therapy for colorectal cancer. Nat Clin Pract Gastroenterol Hepatol. 2009;6:108-20.

4. van Tonder A, Joubert AM, Cromarty AD. Limitations of the 3-(4,5-dimethylthiazol-2-yl)-2,5-diphenyl-2H-tetrazolium bromide (MTT) assay when compared to three commonly used cell enumeration assays. BMC Res Notes. 2015:8:47.

5. Gillet JP, Varma S, Gottesman MM. The clinical relevance of cancer cell lines. J Natl Cancer Inst. 2013:105:452-8.

6. Harris LA, Frick PL, Garbett SP, Hardeman KN, Paudel BB, Lopez CF, Quaranta $\checkmark$, Tyson CR. An unbiased metric of anti-proliferative drug effect in vitro. Nat Methods. 2016;13:497-502.

7. Hsieh $\mathrm{CH}$, Chen YD, Huang SF, Wang HM, Wu MH. The effect of primary cancer cell culture models on the results of drug chemosensitivity assays: the application of perfusion microbioreactor system as cell culture vessel. Biomed Res Int. 2015;2015:470283.

8. Johnson Jl, Decker S, Zaharevitz D, Rubinstein LV, Venditti JM, Schepartz S, Kalyandrug S, Christian M, Arbuck S, Hollingshead M, Sausville EA. Relationships between drug activity in $\mathrm{NCl}$ preclinical in vitro and in vivo models and early clinical trials. Br J Cancer. 2001;84:1424-31.

9. Avril T, Vauléon $\mathrm{E}$, Chevet $\mathrm{E}$. Endoplasmic reticulum stress signaling and chemotherapy resistance in solid cancers. Oncogenesis. 2017:6:e373.

10. Riss TL, Moravec RA, Niles AL, Duellman S, Benink HA, Worzella TJ, Minor L. Cell viability assays. In: Sittampalam GS, Coussens NP, Brimacombe K, Grossman A, Arkin M, Auld D, Austin C, Baell J, Bejcek B, Chung TDY, Dahlin JL, Devanaryan V, Foley TL, Glicksman M, Hall MD, Hass JV, Inglese J, Iversen PW, Kahl SD, Kales SC, Lal-Nag M, Li Z, McGee J, McManus O, Riss T, Trask Jr OJ, Weidner JR, Xia M, Xu X, editors. Assay guidance manual, vol. 2004. Bethesda: Eli Lilly \& Company and the National Center for Advancing Translational Sciences; 2016. p. 355-86.

11. Ulukaya E, Colakogullari M, Wood EJ. Interference by anti-cancer chemotherapeutic agents in the MTT-tumor chemosensitivity assay. Chemotherapy. 2004;50:43-50.

12. Howard DH, Bach PB, Bern ER, Conti RM. Pricing in the market for anticancer drugs. J Econ Perspect. 2015;29:139-62.

13. Eckhouse $S$, Lewison $G$, Sullivan R. Trends in the global funding and activity of cancer research. Mol Oncol. 2008:2:20-32.

14. National Institutes of Health. NIH Management Fund. In: SSF, and GSA Rent FY 2016. 2017. https://www.cancer.gov/about-nci/budget/fact-book/data/ management-fund. Accessed 2 Sep 2017.

15. National Institutes of Health. Estimates of funding for various research. In: Condition, and disease categories (RCDC). 2017. https://report.nih.gov/ categorical_spending.aspx. Accessed 2 Sep 2017.

16. American Cancer Society. Rising global cancer epidemic. In: Infographics. 2016. https://www.cancer.org/research/infographics-gallery/rising-globa l-cancer-epidemic.html. Accessed 3 Sep 2017.

17. Japanese Cancer Research Resource Bank, Japan. 2015. http://www.jhsf or.jp/bank/CellName.html. Accessed 6 Mar 2018.

18. Alshammari MA, Alshammari TK, Laezza F. Improved methods for fluorescence microscopy detection of macromolecules at the axon initial segment. Front Cell Neurosci. 2016;10:5.

19. Loannidis JPA. Why most clinical research is not useful. PLoS Med. 2016:13:e1002049

20. Bernas T, Dobrucki J. Mitochondrial and nonmitochondrial reduction of MTT: interaction of MTT with TMRE, JC-1, and NAO mitochondrial fluorescent probes. Cytometry. 2002;47:236-42.

21. Berridge MV, Tan AS. Characterization of the cellular reduction of 3-(4,5-dimethylthiazol-2-yl)-2,5-diphenyltetrazolium bromide (MTT): subcellular localization, substrate dependence, and involvement of mitochondrial electron transport in MTT reduction. Arch Biochem Biophys. 1993:303:474-82.

22. Chakrabarti R, Kundu S, Kumar S, Chakrabarti R. Vitamin A as an enzyme that catalyzes the reduction of MTT to formazan by vitamin C. J Cell Biochem. 2000:80:133-8. 
23. Stepanenko AA, Dmitrenko W. Pitfalls of the MTT assay: direct and off-target effects of inhibitors can result in over/underestimation of cell viability. Gene. 2015;574:193-203.

24. Baker DD, Chu M, Oza U, Rajgarhia V. The value of natural products to future pharmaceutical discovery. Nat Prod Rep. 2007;24:1225-44.

25. Jelliffe RW, Schumitzky A, Bayard D, Fu X, Neely M. Describing assay precision-reciprocal of variance is correct, not CV percent: its use should significantly improve laboratory performance. Ther Drug Monit. 2015;37:389-94.

26. Natarajan S, Remick DG. The ELISA standard save: calculation of sample concentrations in assays with a failed standard curve. J Immunol Methods. 2008;336:242-5.

27. Bodai Bl, Tuso P. Breast cancer survivorship: a comprehensive review of longterm medical issues and lifestyle recommendations. Perm J. 2015;19:48-79.
28. Baba Al, Catoi C. Tumor cell morphology. Bucharest: The Publishing House of the Romanian Academy; 2007.

29. D’Anselmi F, Valerio M, Cucina A, Galli L, Proietti S, Dinicola S, Pasqualato A Manetti C, Ricci G, Giuliani A, Bizzarri M. Metabolism and cell shape in cancer: a fractal analysis. Int J Biochem Cell Biol. 2011;43:1052-8.

30. Fritz E, Ludwig $H$, Kundi M. Prognostic relevance of cellular morphology in multiple myeloma. Blood. 1984;63:1072-9.

31. Patafio FM, Brooks SC, Wei X, Peng Y, Biagi J, Booth CM. Research output and the public health burden of cancer: is there any relationship? Curr Oncol. 2016;23:75-80
Ready to submit your research? Choose BMC and benefit from:

- fast, convenient online submission

- thorough peer review by experienced researchers in your field

- rapid publication on acceptance

- support for research data, including large and complex data types

- gold Open Access which fosters wider collaboration and increased citations

- maximum visibility for your research: over $100 \mathrm{M}$ website views per year

At BMC, research is always in progress.

Learn more biomedcentral.com/submissions 